CZASOPISMO INŻYNIERII LĄDOWEJ, ŚRODOWISKA I ARCHITEKTURY JOURNAL OF CIVIL ENGINEERING, ENVIRONMENT AND ARCHITECTURE

JCEEA, t. XXXIII, z. 63 (4/16), październik-grudzień 2016, s. 581-588

Marcin ZYGMUNT ${ }^{1}$

Dariusz GAWIN ${ }^{2}$

\title{
ANALIZA ZASTOSOWANIA TECHNIK DSM W CELU REDUKCJI SZCZYTOWEGO ZAPOTRZEBOWANIA MOCY CHLODNICZEJ DLA ZESPOŁU BUDYNKÓW UŻYTECZNOŚCI PUBLICZNEJ
}

\begin{abstract}
W artykule przedstawiono analizę wyników symulacji energetycznych dotyczących grupy obiektów użyteczności publicznej o zróżnicowanej funkcji połączonych w lokalny obszar bilansowania w celu redukcji szczytowej mocy elektrycznej w okresie letnim. Przeanalizowano zapotrzebowanie na moc chłodniczą obiektów tego obszaru w okresie doby w polskich warunkach klimatycznych oraz redukcję mocy szczytowej w wyniku zastosowania technik DSM (ang. Demand Side Management) w badanych obiektach. W pracy rozpatrzono zastosowanie technik DSM: aktywnej - wstępnego schładzania obiektów w godzinach wczesno-porannych, oraz technik pasywnych - zmiany pojemności cieplnej elementów budynku oraz zastosowanie materiałów zmienno-fazowych w ich obudowie zewnętrznej. Zastosowanie w/w technik przeanalizowano także pod kątem ich opłacalności finansowej. Przeprowadzone analizy pokazują wysoki potencjał stosowania technik DSM w celu ograniczenia zapotrzebowania na moc chłodniczą w okresach szczytowego obciążenia sieci elektroenergetycznej. Dodatkowo wykazano, że połączenie szeregu obiektów o zróżnicowanej funkcji w jeden obszar bilansowania może prowadzić do bardziej równomiernego zapotrzebowania na moc elektryczną w ciągu doby. Przeprowadzona analiza kosztowa wykazuje korzyści finansowe płynące z zastosowania technik DSM.
\end{abstract}

Słowa kluczowe: techniki DSM - Demand Side Management, lokalny obszar bilansowania, wstępne schładzanie obiektu, obniżenie szczytowej mocy elektrycznej, równomierne w czasie obciążenie sieci elektroenergetycznej, aktywne i pasywne techniki DSM, pojemność cieplna, materiały zmienno-fazowe

${ }^{1}$ Autor do korespondencji / corresponding author: Marcin Zygmunt, Politechnika Łódzka, Katedra Fizyki Budowli i Materiałów Budowlanych, al. Politechniki 6, 90-924 Łódź, tel. (42)-631-35-56; marcin.zygmunt@p.lodz.pl

2 Dariusz Gawin, Politechnika Łódzka, Katedra Fizyki Budowli i Materiałów Budowlanych, al. Politechniki 6, 90-924 Łódź, tel. (42)-631-35-56; dariusz.gawin@p.lodz.pl 


\section{Wprowadzenie}

Analiza danych Polskich Sieci Elektroenergetycznych (PSE) [1] wyraźnie wskazuje, że wraz z rozwojem gospodarczym Polski rośnie zużycie energii elektrycznej. Obecne prognozy przewidują, że zapotrzebowanie na energię elektryczną w naszym kraju będzie dalej wzrastać, a co za tym idzie, zwiększy się również zapotrzebowanie na moc szczytową. W okresie ostatnich lat obserwuje się w naszym kraju rosnące $\mathrm{z}$ roku na rok zapotrzebowanie na moc elektryczną w okresie letnim. Wynika to z coraz częstszego stosowania w obiektach budowlanych instalacji chłodzących wskutek stopniowego ocieplania się klimatu w skali globalnej, w tym w Polsce. Analizując przykładowy, dobowy rozkład zapotrzebowania na moc w okresie letnim [2], można wyróżnić okres szczytowego obciążenia sieci elektroenergetycznej. Z punktu widzenia dostawcy energii, dobowy rozkład zapotrzebowania na moc elektryczną powinien być jak najbardziej równomierny w czasie, a maksymalne zapotrzebowanie na moc nie powinno zbytnio wahać się w pobliżu szczytowych możliwości sieci elektroenergetycznej. Rozwiązaniem, które pozwala uzyskać w/w efekt, poza magazynowaniem energii w elektrowniach szczytowo-pompowych, jest zastosowanie technik DSM (ang. Demand Side Management) [3-5]. Działania tego typu polegają na ograniczeniu zużycia energii przez odbiorców w okresach szczytowego zapotrzebowania i przesunięciu go do okresów mniejszego obciążenia sieci, a co za tym idzie - zmniejszenie wymaganej mocy generatorów prądu, zainstalowanych u dostawcy energii. W niniejszym artykule przeanalizowano przykładową grupę budynków użyteczności publicznej, które odpowiadają za ok. 20\% całkowitego zużycia energii elektrycznej w naszym kraju. Nośnikiem energii systemów chłodzących obiektów użyteczności publicznej jest zwykle energia elektryczna.

Coraz częściej rozpatrywanym w literaturze rozwiązaniem jest łączenie grupy budynków o różnych funkcjach i zróżnicowanym w czasie zapotrzebowaniu energii, w większe sieci typu ,smart grid” $[6,7]$. Artykuł poświęcono analizie wpływu zastosowania technik DSM dla pewnej wirtualnej grupy obiektów użyteczności publicznej, zlokalizowanych w Polsce, połączonych w obszar bilansowania (hipotetycznie położony w centrum miasta). Przeanalizowano rozkład w czasie zapotrzebowania na moc chłodniczą oraz redukcję szczytowego zapotrzebowania na moc elektryczną w godzinach dobowego szczytu w okresie letnim.

\section{Opis analizowanych obiektów}

Przedmiotem analizy były obiekty użyteczności publicznej o zróżnicowanej funkcji: budynek biurowy, multipleks kinowy, hotel i market wielkopowierzchniowy, analizowane łącznie przy założeniu, że stanowią one jeden obszar bilan- 
sowania energii. Analizowane typy obiektów dobrano na podstawie obserwacji zabudowy centrów dużych miast, gdzie dominują obiekty o w/w funkcjach.

Poniżej przedstawiono krótką charakterystykę badanych obiektów. Narzędziem wykorzystanym do symulacji energetycznych budynków był program komputerowy Design Builder [8] - nakładka na program Energy Plus [9].

Budynek biurowy (Rys. 1.) jest obiektem charakteryzującym się wysokim, 70\% udziałem szklenia powierzchni zewnętrznej. Jest to obiekt 5-kondygnacyjny o powtarzalnym układzie przestrzennym. Analizowanym obszarem jest strefa biurowa o powierzchni użytkowej $688 \mathrm{~m}^{2}$ (z wyłączeniem szybu windowego).

Multipleks kinowy (Rys. 2.) jest obiektem 2-kondygnacyjnym, w którym znajduje się 8 sal kinowych (po 4 na kondygnację). Maksymalna ilość widzów mogących równocześnie przebywać w obiekcie wynosi 2496 osób.

Hotel (Rys. 3.) jest budyniem 10-piętrowym, o kondygnacji powtarzalnej, znajduje się w nim 218 pokoi dwuosobowych.

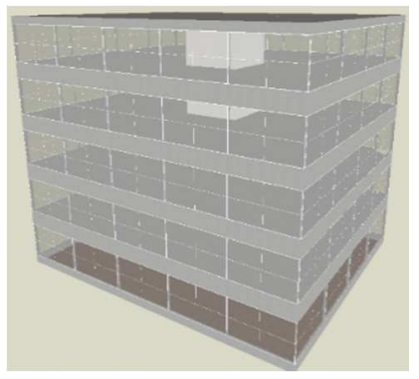

Rys. 1. Wizualizacja analizowanego obiektu biurowego w programie Design Builder

Fig. 1. Visualization of the analyzed office building in the Design Builder code

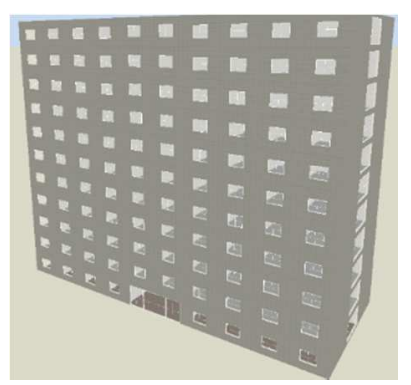

Rys. 3. Wizualizacja analizowanego hotelu w programie Design Builder

Fig. 3. Visualization of the analyzed hotel in the Design Builder code

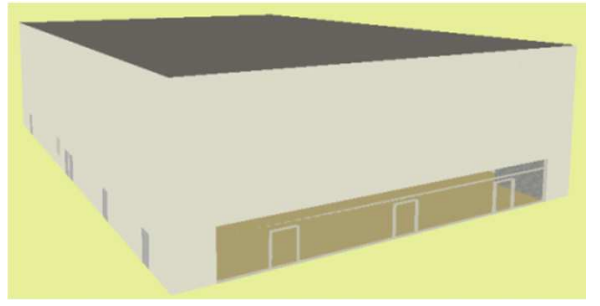

Rys. 2. Wizualizacja analizowanego multipleksu kinowego w programie Design Builder

Fig. 2. Visualization of the analyzed cinema in the Design Builder code

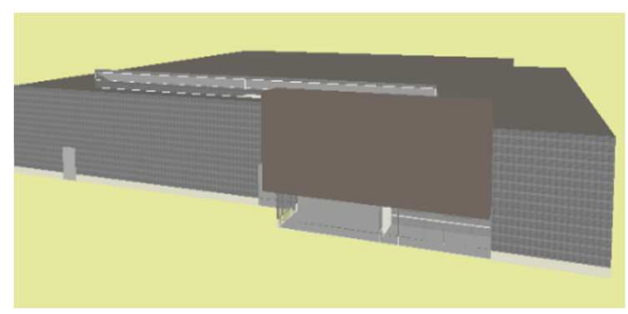

Rys. 4. Wizualizacja analizowanego marketu wielkopowierzchniowego w programie Design Builder

Fig. 4. Visualization of the analyzed large area mall in the Design Builder code 
Ostatnim badanym obiektem jest market wielkopowierzchniowy (Rys. 4.), który jest obiektem parterowym, charakteryzującym się dużą powierzchnią hali sprzedaży - $4200 \mathrm{~m}^{2}$.

Rozpatrywany w niniejszej pracy obszar bilansowania, o funkcjach budynków typowych dla centrum miasta, składał się z następujących obiektów: 6 budynków biurowych, 2 multipleksów kinowych, 2 marketów wielkopowierzchniowych oraz 4 hoteli, w każdym z nich zajmowanych jest 50 pokoi.

Każdy $\mathrm{z}$ analizowanych obiektów charakteryzował się własnym harmonogramem pracy i związanym z tym obciążeniem wewnętrznymi zyskami ciepła. Projektowa temperatura wewnętrzna obiektów przyjęta została na poziomie $24^{\circ} \mathrm{C}$.

\section{Opis przeprowadzonych analiz energetycznych i kosztowych}

Opłacalność zastosowania technik DSM w budynkach użyteczności publicznej przeprowadzono poprzez analizę kosztową proponowanych rozwiązań.

Pierwszym krokiem przeprowadzonych analiz było sprawdzenie wpływu temperatury i czasu schładzania obiektu w godzinach wczesno-porannych (tzw. technika ,precooling”) na redukcję zapotrzebowania na moc elektryczną urządzeń chłodniczych. Sprawdzono warianty obniżania temperatury wewnątrz obiektów do poziomu: $20^{\circ} \mathrm{C}, 21^{\circ} \mathrm{C}$ i $22^{\circ} \mathrm{C}$, w przedziale czasu od godziny $4: 00$ do 8:00, dla różnych długości trwania schładzania wnętrza budynku (od 1 do 4 godzin). Przykładowe wyniki obliczeń, ilustrujące efekty zastosowania opisanej techniki, pokazano na Rys. 5.

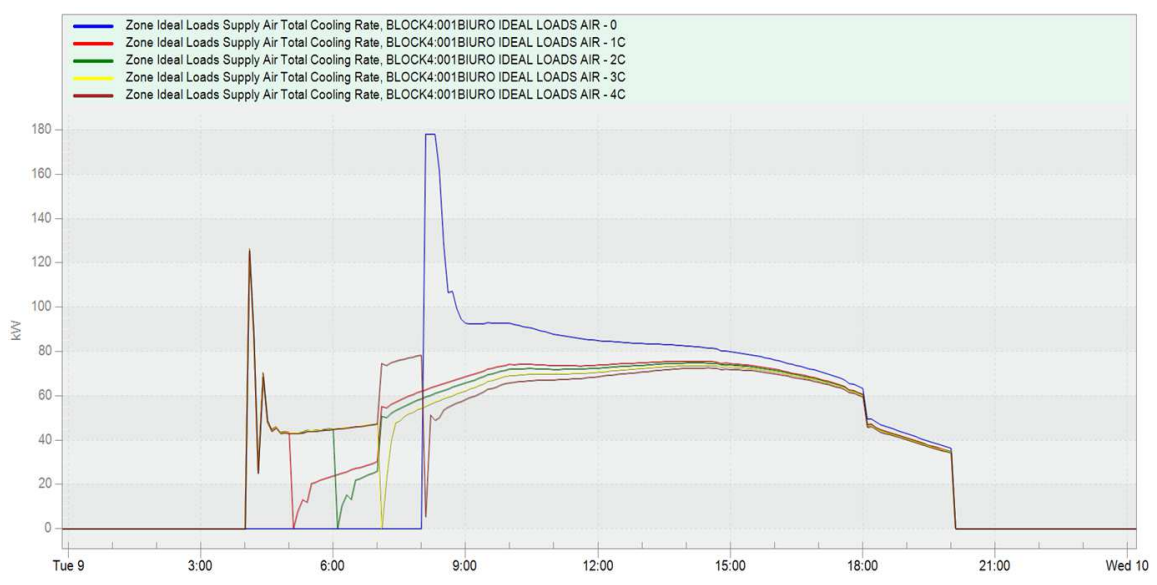

Rys. 5. Dobowy przebieg zapotrzebowania na moc chłodniczą przy wstępnym schładzaniu obiektu biurowego do temperatury $22^{\circ} \mathrm{C}$ w godzinach od 4:00 do 8:00 przez różny okres czasu

Fig. 5. Daily cooling power demand by using precooling to $22{ }^{\circ} \mathrm{C}$ operative temperature level in the office building for various time periods between 4 a.m. and 8 a.m. 
Następnie, sprawdzono opłacalność stosowania powyższej, aktywnej techniki DSM pod kątem osiągnięcia korzyści finansowych. Analizę wykonano przyjmując aktualne taryfy cen energii elektrycznej w Polsce [10]. Obliczone oszczędności (obejmujące całą dobę) płynące z zastosowania schładzania obiektu w godzinach wczesno-porannych zestawiono w Tab. 1. Jak widać w poniższej tabeli, zastosowanie schładzania obiektu biurowego w godzinach wczesnorannych prowadzi do osiągnięcia kilkuprocentowej oszczędności kosztów chłodzenia, w skali doby.

Tabela 1. Wyniki analizy kosztowej dla różnych czasów schładzania obiektu biurowego

Table 1. Results of cost analysis of various precooling time for the building office

\begin{tabular}{|c|c|c|c|c|c|}
\hline \multirow{2}{*}{$\begin{array}{l}\text { Taryfa rozli- } \\
\text { czenia kosztów } \\
\text { energii }\end{array}$} & \multicolumn{5}{|c|}{ Koszty chłodzenia [zł] / Oszczędność kosztów [\%] } \\
\hline & $\begin{array}{l}\text { Bez precoo- } \\
\text { lingu }\end{array}$ & $\begin{array}{c}\text { Precooling } \\
\text { 1h }\end{array}$ & $\begin{array}{c}\text { Precooling } \\
\text { 2h }\end{array}$ & $\begin{array}{c}\text { Precooling } \\
\text { 3h }\end{array}$ & $\begin{array}{c}\text { Precooling } \\
4 \mathrm{~h}\end{array}$ \\
\hline \multirow{2}{*}{ C22a } & 390,69 & 380,31 & 379,54 & 377,90 & 378,37 \\
\hline & - & $2,66 \%$ & $2,85 \%$ & $3,27 \%$ & $3,15 \%$ \\
\hline \multirow{2}{*}{$\mathrm{C22b}$} & 441,20 & 431,08 & 426,85 & 426,37 & 429,39 \\
\hline & - & $2,29 \%$ & $3,25 \%$ & $3,36 \%$ & $2,68 \%$ \\
\hline
\end{tabular}

Ostatnim elementem analizy kosztowej było sprawdzenie opłacalności dodatkowego zastosowania pasywnych technik DSM. W tym celu przeanalizowano:

- zastosowania trzech różnych materiałów fazowo-zmiennych (o charakterystykach pokazanych na Rys. 6.) jako okładziny wewnętrznej ścian zewnętrznych (materiały fazowo-zmienne zastosowano jako granulat dodany przy produkcji płyt karton-gipsowych; brak analizy kosztowej),

- zmiana pojemności cieplnej obudowy zewnętrznej budynku na wysoką (zamiana konstrukcji z płyt warstwowych bądź bloczków z betonu komórkowego na konstrukcję z cegły; brak analizy kosztowej).

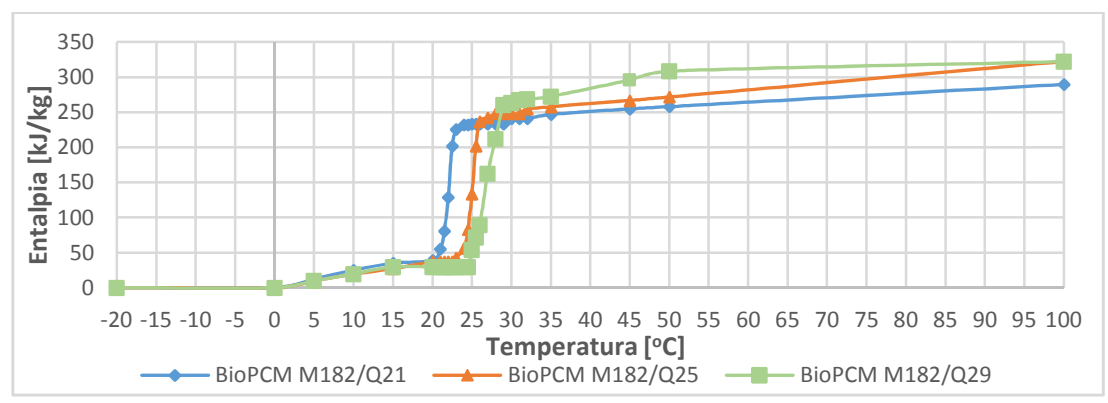

Rys. 6. Zależność entalpii do temperatury dla 3 rozważanych materiałów fazowo-zmiennych

Fig. 6. Dependence of enthalpy vs. temperature for 3 analyzed phase changing materials (PCMs)

Okresem przeprowadzonych symulacji jest ekstremalny tydzień letni typowego roku meteorologicznego, który został wyznaczony zgodnie z [11]. Okres 
analizy to 6-12 lipca, dla którego średnia tygodniowa temperatura wynosiła $21,9^{\circ} \mathrm{C}$. Przykładowe wyniki obliczeń ilustrujące efekty zastosowania materiałów fazowo-zmiennych jako okładziny wewnętrznej ścian zewnętrznych pokazano na Rys. 7.

Wszystkie proponowane rozwiązania, przyjęte w przeprowadzonych symulacjach energetycznych, były analizowane pod kątem zapewnienia właściwych warunków mikroklimatu wewnętrznego. Parametry proponowanych rozwiązań były dobrane tak, aby warunki wewnątrz obiektów zapewniały odczucie komfortu cieplnego [12].

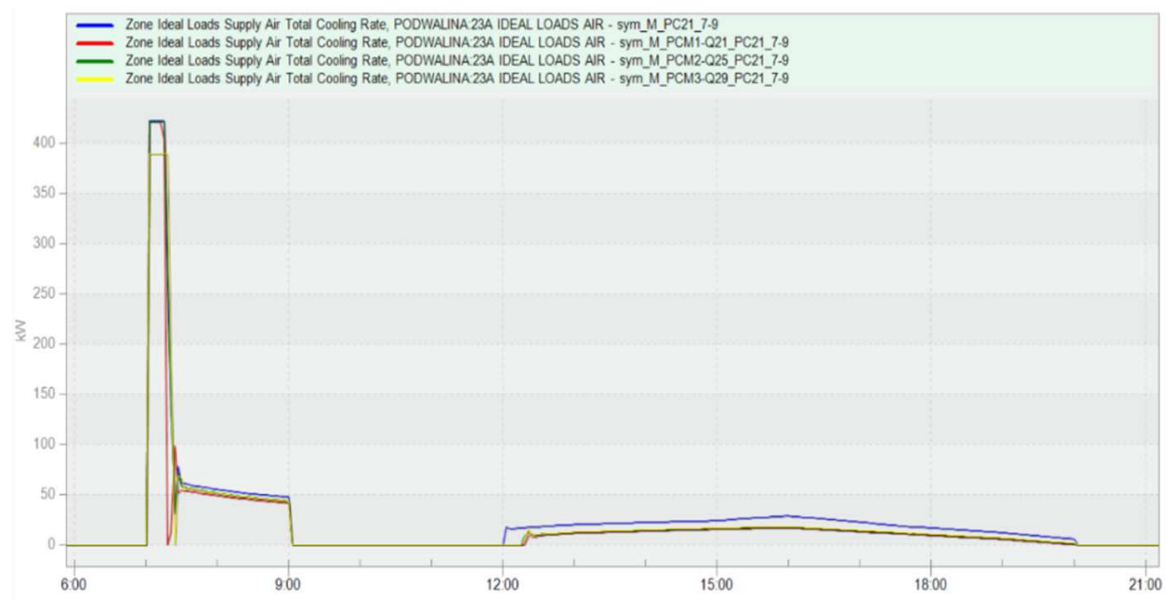

Rys. 7. Dodatkowa redukcja zapotrzebowania na moc chłodniczą dzięki zastosowaniu materiałów fazowo-zmiennych

Fig. 7. Additional reduction of cooling power demand due to application of PCMs

\section{Analiza wyników przeprowadzonych symulacji}

Na Rys. 8. przedstawiono dobowe zapotrzebowanie na moc chłodniczą całego analizowanego obszaru bilansowania.

Sytuację wyjściową - bez stosowania technik DSM - przedstawia linia niebieska. Analizując ten wykres stwierdzono, że dzięki zastosowaniu aktywnej techniki DSM - wstępnego schładzania obiektu w godzinach wczesno-rannych (linia ciągła), zredukowano zapotrzebowanie na moc chłodniczą w okresie szczytowego obciążenia sieci. Rozpatrywany okres szczytowego obciążenia przypada na godz. 9:00 - 15:00. Dla analizowanych przypadków wstępnego schładzania obiektów udało się zredukować zapotrzebowanie na moc chłodniczą od $8,3 \%$ do $31,6 \%$, a całkowite zużycie energii na potrzeby chłodzenia zredukowano o 19,7\% w okresie szczytowego obciążenia sieci elektroenergetycznej.

Stosując pasywne techniki DSM (linia kropkowana) łącznie ze wstępnym schładzaniem obiektów udało się osiągnąć dodatkowe korzystne efekty. Zapo- 
trzebowanie na moc chłodniczą zredukowano od $9,7 \%$ do $32,1 \%$, a całkowite zużycie energii na potrzeby chłodzenia zmniejszono o ok. $20,5 \% \mathrm{w}$ analizowanym okresie doby.

Należy zauważyć, że dzięki zastosowaniu technik DSM zapotrzebowanie na moc chłodniczą jest bardziej równomiernie rozłożone w czasie oraz udało się zredukować maksymalną wartość dobowego zapotrzebowania na tę moc.

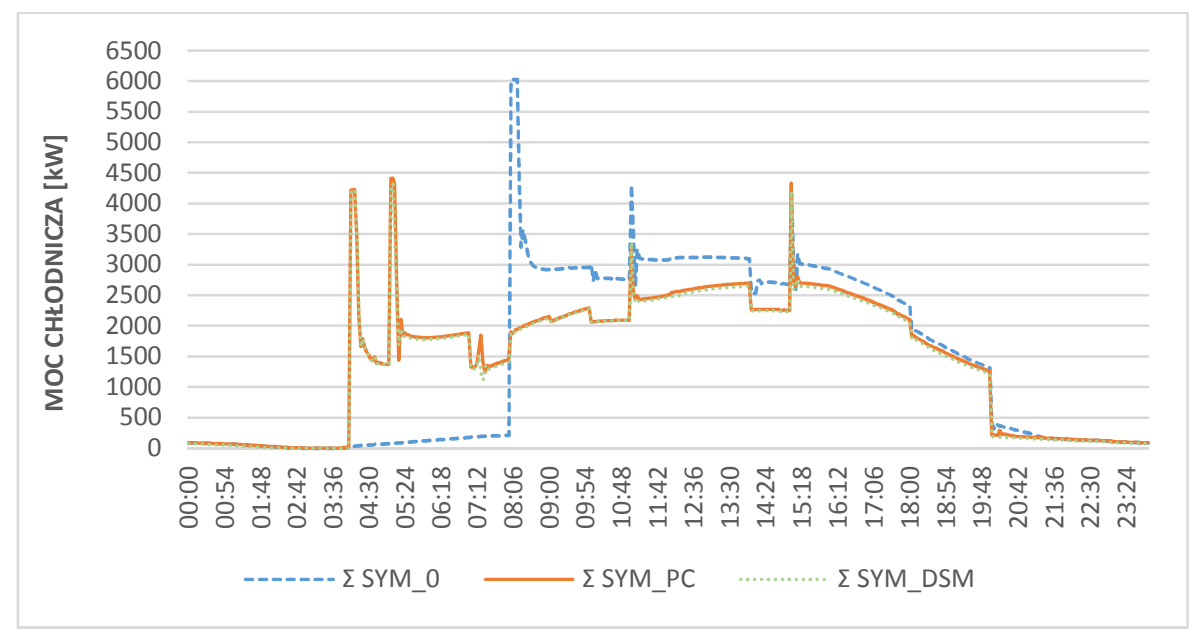

Rys. 8. Rozkład dobowy zapotrzebowania na moc chłodniczą różnych wariantów DSM badanego obszaru

Fig. 8. Daily cooling power demand for different DSM techniques to subject area

\section{Wnioski}

Wyniki wykonanych analiz pokazują, że zastosowanie aktywnych i pasywnych technik typu „Demand Side Management” w lokalnym obszarze bilansowania obiektów użyteczności publicznej o różnej funkcji, może prowadzić w okresie letnim do:

- bardziej równomiernego rozkładu w czasie zapotrzebowania na moc elektryczną urządzeń chłodniczych,

- redukcji szczytowego zapotrzebowania na moc elektryczną tych urządzeń,

- odciążenia sieci elektroenergetycznej w okresie dobowego szczytu,

- osiągnięcia wymiernych korzyści finansowych z ich zastosowania.

Przeprowadzone analizy wymagają walidacji poprzez porównanie wyników symulacji z rzeczywistymi danymi zużycia energii i zapotrzebowania na moc.

\section{Literatura}

[1] Polskie Sieci Elektroenergetyczne, Plan rozwoju w zakresie zaspokojenia obecnego i przyszłego zapotrzebowania na moc elektryczną na lata 2016-2025, Konstancin-Jeziorna, 2014. 
[2] Polskie Sieci Elektroenergetyczne - www.pse.pl \{dostęp 30.04.2016 r.\}.

[3] Lawrence Berkeley National Laboratory, Introduction to Commercial Building Control Strategies and Techniques for Demand Response, Berkeley, 2007.

[4] Lawrence Berkeley National Laboratory, Design and Implementation of an Open, Interoperable Automated Demand Response Infrastructure, Berkeley, 2007.

[5] J. Khoury, R. Mbayed, G. Salloum, E. Monmasson, Predictive demand side management of a residential house under intermittent primary energy source conditions, Energy and Buildings, 2015.

[6] R. Velik, P. Nicolay, Energy management in storage-augmented, grid connected prosumer buildings and neighborhoods using a modified simulated annealing optimization, Computer \& Operations Research, 2015.

[7] Smart Grid Gotland - electricity network for the future - www.smartgridgotland.se/eng/ \{dostęp 10.05.2016 r.\}.

[8] DesignBuilder Software - www.designbuilder.co.uk. \{dostęp 15.03.2016 r.\}.

[9] EnergyPlus Engineering Reference, Illinois 2014.

[10] Energa - www.energa.pl \{dostęp 30.04.2016 r.\}.

[11] Gawin D., Kossecka E., Typowy rok meteorologiczny do symulacji wymiany ciepła i masy w budynkach, Politechnika Łódzka, 2002.

[12] Fanger P. O., Komfort cieplny, Arkady, 1974.

\section{ANALYSIS OF APPLYING VARIOUS DEMAND SIDE MANAGEMENT TECHNIQUES FOR REDUCTION OF COOLING POWER DEMAND PEAK FOR THE GROUP OF PUBLIC UTILITY BUILDINGS}

\section{S u m m a r y}

The aim of this article is analysis of energy simulation for a group of public utility buildings connected into one local assess area in order to reduce the cooling power demand peak in summer time. The analysis deals with the daily cooling energy demand of the area for the climatic conditions of Poland and the reduction of peak power demand by using Demand Side Management techniques applied in these buildings. For this end the use of various DSM techniques: active one, i.e. a decrease of operative temperature in the buildings in early morning and two passive techniques, i.e. thermal capacity increase for construction elements and use of phase changing materials in external walls, were examined. Moreover, use of the abovementioned techniques was analyzed considering their financial benefits. The analysis showed a high potential of DSM techniques application to reduce the cooling power demand during electricity grid peak hours. Additionally, connecting various public utility buildings into one assess area may lead to more steady daily electricity power demand. The analysis also showed some financial benefits of application of the DSM techniques considered.

Keywords: DSM - demand side management, micro-grids, precooling, peak energy, reducing peak electrical power, active \& passive techniques DSM, thermal capacity, phase-change materials

DOI:10.7862/rb.2016.302

Przestano do redakcji: $30.06 .2016 r$.

Przyjęto do druku: 20.12.2016 r. 